Check for updates

Cite this: RSC Adv., 2018, 8, 32084

\title{
Reduction of Cd accumulation in pak choi (Brassica chinensis L.) in consecutive growing seasons using mercapto-grafted palygorskite
}

\author{
Lizhi He, ${ }^{a} \mathrm{Na} \mathrm{Li},{ }^{\mathrm{b}}$ Xuefeng Liang, (D) *a Xiuling Yin, ${ }^{\mathrm{b}}$ Qingqing Huang, ${ }^{\mathrm{a}}$ Lin Wang, ${ }^{a}$ \\ Yuebing $\mathrm{Sun}^{\mathrm{a}}$ and Yingming $\mathrm{Xu}^{\star \mathrm{a}}$
}

Cd contamination in agricultural fields poses a potential human health risk via food chain exposure. Proper remediation methods are critical to ensure the adequate safety of agricultural food products. In the current study, mercapto-grafted palygorskite (MP), a novel immobilization agent, was selected for the remediation of $\mathrm{Cd}$-contaminated acid soils in pot experiments. Pak choi was used as the model plant. MP significantly reduced $\mathrm{Cd}$ accumulation in the shoots and roots of pak choi grown in Xiangtan and Guiyang soils in comparison to the control, in consecutive growing seasons, and the minimum $\mathrm{Cd}$ contents in shoots were less than the maximum permitted level proposed by the Codex Alimentarius Commission of FAO and WHO. Further, MP decreased the phytoavailable $\mathrm{Cd}$ content in soils determined using the diffusive gradient technique in thin-films in consecutive growing seasons with the maximum reductions of $86.26 \%$ and $89.51 \%$ respectively. These findings indicated that MP had a remarkable Cd immobilization efficiency in soils. MP had no obvious promotion impact on the $\mathrm{pH}$ value of either soil sample, but decreased the zeta potentials of both soil samples significantly, and then resulted in increases of the maximum sorption amounts of $\mathrm{Cd}$ of both soil samples. The results indicated MP could achieve remediation of $\mathrm{Cd}$-contaminated soil by enhancing the sorption of $\mathrm{Cd}$ contaminants and the chemical sorption of $\mathrm{Cd}^{2+}$. The available sulfur content in both soils increased and soil enzyme activities, such as that of urease, were enhanced, thereby alleviating $\mathrm{Cd}$-induced oxidation. These improvements of the index of soil environmental and biological qualities indicated that MP was environmentally friendly and compatible. The high performance of MP even at a small dosage suggested that when scaled up to agricultural operations over a large-area, MP had great potential to reduce $\mathrm{Cd}$ accumulation in vegetables, thereby ensuring the food safety of vegetables.

Received 10th June 2018 Accepted 7th September 2018 DOI: 10.1039/c8ra04952a rsc.li/rsc-advances agricultural managers to reduce $\mathrm{Cd}$ accumulation in vegetables and ensure adequate food safety for consumers.

Various methods have been proposed to reduce Cd uptake and subsequent translocation in vegetables. Several methods utilize an in situ application of amendments or immobilization agents to soils such as clay minerals, ${ }^{2}$ biochar, ${ }^{3,4}$ red mud $^{5-7}$ and iron-silicon material. ${ }^{8}$ Another approach includes foliar spraying of liquid amendments as numerous studies have shown that the application of certain compounds containing $\mathrm{Si}^{9,10}$ $\mathrm{Se},{ }^{11,12}$ or chitooligosaccharide, ${ }^{13}$ could significantly reduce $\mathrm{Cd}$ accumulation in plants. Alternatively, careful selection of low Cd-accumulating vegetable cultivars or pollution-safe cultivars was another effective strategy to reduce Cd uptake by vegetables and subsequent human exposure. ${ }^{14,15}$

Foliar spraying of liquid amendments and culturing low Cdaccumulating vegetable cultivars can reduce $\mathrm{Cd}$ accumulation in vegetables, but their targets are plants not soils, especially $\mathrm{Cd}$ pollutants at a high-risk level in the soils. In situ Cd immobilization in soils could minimize health risks by reducing the uptake of heavy metals by vegetables. In situ immobilization can 
be achieved by changing the form of the heavy metals or their microenvironments in soils using immobilization agents that can adsorb, complex, or precipitate heavy metals in soil to inhibit their mobility and bioavailability. Labile $\mathrm{Cd}$ fractions in soils are most easily absorbed by plants, which could be determined by conventional methods, such as chemical extraction and passive sampling method such as the diffusive gradients in thin films (DGT) technology. DGT with significant advantages is a promising tool for in situ measuring the labile Cd concentration in soils. ${ }^{16}$

Several, immobilization agents have been reported to reduce $\mathrm{Cd}$ accumulation in vegetables, ${ }^{17}$ but these methods are limited as many are pH-regulating agents with high application dosages. ${ }^{2}$ Development of novel high-performance and lower cost immobilization agents is urgently needed.

Pak choi (Brassica chinensis L.) is an important leafy vegetable widely grown and consumed in China. In the present study, pot experiments using pak choi as a model plant, were conducted to investigate the remediation capabilities of a novel immobilization agent, mercapto-grafted palygorskite, with respect to soils and plants.

\section{Materials and methods}

\subsection{Preparation of mercapto-grafted palygorskite}

To prepare mercapto-grafted palygorskite (MP), a novel immobilization agent, mercapto groups were grafted onto the surface of natural palygorskite by inducing covalent bond formation using a high-speed shear method. ${ }^{18}$ 3-Mercaptopropyltrimethoxysilane (MPTMS) was bought from Sigma-Aldrich, Shanghai. Natural palygorskite was obtained from Chuzhou, Anhui Province, China. Natural palygorskite of $50 \mathrm{~g}$ sieved through a $0.15 \mathrm{~mm}$ mesh was dispersed in $950 \mathrm{~mL}$ water and then stirred with an electronic disperser (T10 basic, IKA) at $10000 \mathrm{rpm}$ for $15 \mathrm{~min}$ to form aqueous gel. MPTMS of $50 \mathrm{~g}$ was added to the gel and stirred at $10000 \mathrm{rpm}$ for $15 \mathrm{~min}$. Then all the products were cured in an oven at $100{ }^{\circ} \mathrm{C}$ for $24 \mathrm{~h}$. The dried powder was collected for further pot and sorption experiments.

\subsection{Pot experiment design}

Cd contaminated soil samples for pot experiments were collected from agricultural fields in Guiyang and Xiangtan, Hunan province. The Guiyang and Xiangtan samples were derived from different parent materials and contaminated by non-ferrous metal smelting and sewage irrigation, respectively. The soil physiochemical properties are listed in Table 1.
The pot experiment, with pak choi as the model plant, was conducted in an intelligent greenhouse. Soil samples of $4.0 \mathrm{~kg}$ sieved through a $1 \mathrm{~mm}$ mesh were prepared. Three application dosages of MP were used, $0.1 \%$ (weight/weight) (MP1), $0.2 \%$ (MP2) and $0.3 \%$ (MP3), along with a control soil sample (CK) without any immobilization agent. MP was thoroughly mixed with soil samples manually, and then transferred to a plastic pot for the plant cultivation. Each treatment was prepared in triplicate.

In the first growing season, 6 seeds of pak choi were planted into each pot 20 days after the addition of MP. The experiment was carried out under natural lighting. Pots were randomized in blocks on the cultivation bed and their positions were changed weekly. Pak choi was routinely irrigated with deionized water to maintain a $60 \%$ soil water content. After a 50 day growing period, the plants were harvested, weighed, and carefully washed with deionized water, and then separated into roots and shoots. All samples were oven dried $\left(75^{\circ} \mathrm{C}\right)$ to a constant weight. The fresh weight and dry weight of each plant sample were recorded. The dry plant samples were ground using a stainlesssteel mill and passed through a $0.25 \mathrm{~mm}$ sieve for further analyses. The second growing season began 10 days after the harvest of the first growing season. The soils samples were set to $60 \%$ field capacity, without any additional MP. Six seeds of pak choi were planted into each pot. The management and harvesting procedures were the same as the first growing season.

\subsection{Sorption experiments}

To investigate the amount of $\mathrm{Cd}^{2+}$ sorption on soil samples amended with MP, sorption experiments were conducted. Soil samples $(0.05 \mathrm{~g})$ were placed in centrifugal tubes and $25 \mathrm{~mL}$ of $1.0 \mathrm{mmol} \mathrm{L}{ }^{-1} \mathrm{Cd}\left(\mathrm{NO}_{3}\right)_{2}$ solution added. Samples were then shaken at room temperature for $300 \mathrm{~min}$ in a thermostatic water bath shaker, and then the suspensions were centrifuged at a speed of $13000 \mathrm{rpm}$. The supernatant was collected to determine the equilibrium $\mathrm{Cd}^{2+}$ concentrations using an atomic absorption spectrometer (ZEEnit 700P, Analytik Jena, Germany). The amount of sorption was calculated from the decrease in $\mathrm{Cd}^{2+}$ concentration in aqueous solution.

\subsection{Analytical methods}

(1) Cd contents in plants and soils. A $0.50 \mathrm{~g}$ sample of pak choi powder was digested using a $10 \mathrm{~mL}$ mixed solution of $\mathrm{HNO}_{3}-\mathrm{HClO}_{4}(4: 1, \mathrm{v} / \mathrm{v})$. Soil samples were digested in a $\mathrm{HNO}_{3}{ }^{-}$ $\mathrm{HF}^{-} \mathrm{HClO}_{4}(2: 2: 1, \mathrm{v} / \mathrm{v} / \mathrm{v})$ solution with a $1: 25$ soil : liquid ratio. The phytoavailable Cd concentration in soil samples was

Table 1 Basic physical and chemical properties of the selected soil samples

\begin{tabular}{|c|c|c|c|c|}
\hline \multirow[b]{2}{*}{ Location } & \multirow[b]{2}{*}{ Average pH } & \multirow[b]{2}{*}{ Parent material } & \multirow{2}{*}{$\frac{\text { Total Cd content }}{\mathrm{mg} \mathrm{kg}^{-1}}$} & \multirow{2}{*}{$\frac{\mathrm{CEC}}{\mathrm{cmol} \mathrm{kg}^{-1}}$} \\
\hline & & & & \\
\hline Xiangtan & 5.2 & Red soil & $0.62 \pm 0.06$ & $16.8 \pm 2.6$ \\
\hline
\end{tabular}


sampled using DGT, with piston-type DGT devices (Weishen DGT Research Ltd). ${ }^{19}$ The DGT deployment and soil solution collection were conducted according to the procedures proposed by Zhang. ${ }^{20} \mathrm{Cd}$ concentrations in the digested solutions were determined using an inductively coupled plasma mass spectrometer (iCAP Q, Thermo Scientific, US).

(2) $\mathrm{pH}$ and zeta potentials. Soil $\mathrm{pH}$ was measured at a soil : water ratio of $1: 2.5(\mathrm{w} / \mathrm{v})$ using a $\mathrm{pH}$ meter (PB-10, Sartorius, Germany). The zeta potentials of soil samples were measured by a micro-electrophoresis meter (JS94H, Powereach, China). ${ }^{21}$ The available sulfur in soil samples was extracted using $0.5 \mathrm{~mol} \mathrm{~L}^{-1} \mathrm{NaHCO}_{3}$ solution at $\mathrm{pH} \quad 8.5$ and a soil : solution ratio of $1: 5(\mathrm{w} / \mathrm{v})$, and quantified using the Johnson-Nishita procedure. ${ }^{22}$

(3) Soil enzyme activities. Soil enzyme activities were determined using assay kits produced by Suzhou Comin biotechnology Co. (Ltd) and based on the methods proposed by Soil Science Society of America. ${ }^{23-25}$ Urease activity was estimated by the indophenol blue colorimetric determination of ammonium released during a soil sample incubation with urea at $37{ }^{\circ} \mathrm{C}$ for $24 \mathrm{~h}$, expressed as $\mu \mathrm{g} \mathrm{NH}_{4}{ }^{+}-\mathrm{N}$ per $\mathrm{d}$ per $\mathrm{g}$. Catalase activity in soil was measured by ultraviolet (UV) spectrophotometry at $240 \mathrm{~nm}$, expressed as $\mu \mathrm{mol} \mathrm{H}_{2} \mathrm{O}_{2}$ per $\mathrm{d}$ per $\mathrm{g}$. Soil sucrase was determined by the dinitrosalicylic acid colorimetric method, where a UV spectrophotometer is operated at $510 \mathrm{~nm}$. Soil peroxidase oxidizes organic matter in the presence of $\mathrm{H}_{2} \mathrm{O}_{2}$ to produce cesium, which can be analyzed by UV spectrophotometry at $430 \mathrm{~nm}$. Soil peroxidase activity can be expressed as $\mathrm{mg}$ purple galloside per $\mathrm{d}$ per $\mathrm{g}$.

\subsection{Statistical analysis}

Results of the replicated experiments are expressed as mean \pm standard deviation. Statistical analyses were performed using SPSS 22.0. Data from experiments with multiple treatments were analyzed using a one-way ANOVA followed by Duncan's multiple range test. Differences were considered significant when $p<0.05$. All figures were made with OriginPro 2017 .

\section{Results and discussion}

\subsection{Effect of MP on the biomass of pak choi}

Total fresh biomass of the vegetable is a critical factor for agricultural production. The minimum requirement for remediation agents is that that do not significantly reduce crop yields. As shown in Fig. 1, MP had no significant effect on the pak choi biomass compared to the control in either the first or second growing season $(p>0.05)$. The biomass of pak choi was in the normal range and the growth of pak choi in the selected soils was not significantly impacted by the stress of Cd contamination.

\subsection{Effects of MP on Cd accumulation in pak choi}

Cd accumulation in pak choi is the determining factor for the success of remediation agents. Immobilization effects of MP can be represented by the reduction of $\mathrm{Cd}$ accumulation in shoots and roots of pak choi, as shown in Fig. 2 and Table 2. Cd content in shoots of pak choi CK samples grown in Guiyang and Xiangtan soils during the first growing season were 0.99 and $0.63 \mathrm{mg} \mathrm{kg}^{-1}$, respectively. The shoot Cd content in CK sampled values from the second growing season were 0.53 and $0.69 \mathrm{mg}$ $\mathrm{kg}^{-1}$, respectively. All values were much higher than $0.20 \mathrm{mg}$ $\mathrm{kg}^{-1} \mathrm{Cd}$ maximum permitted level in China according to the Maximum Levels of Contaminants in Foods (GB 2762-2017), and the guideline for leafy vegetables according to the Codex General Standard for Contaminants and Toxins in Food and Feed (Codex Stan 193-1995) proposed by the Codex Alimentarius Commission of FAO and WHO.

Although MP had no significant effects on the biomass of pak choi, MP decreased Cd contents in shoots grown in Guiyang and Xiangtan soil samples by $59.44-76.33 \%$ and $37.87-75.51 \%$, respectively, during the first growing season. Therefore, MP
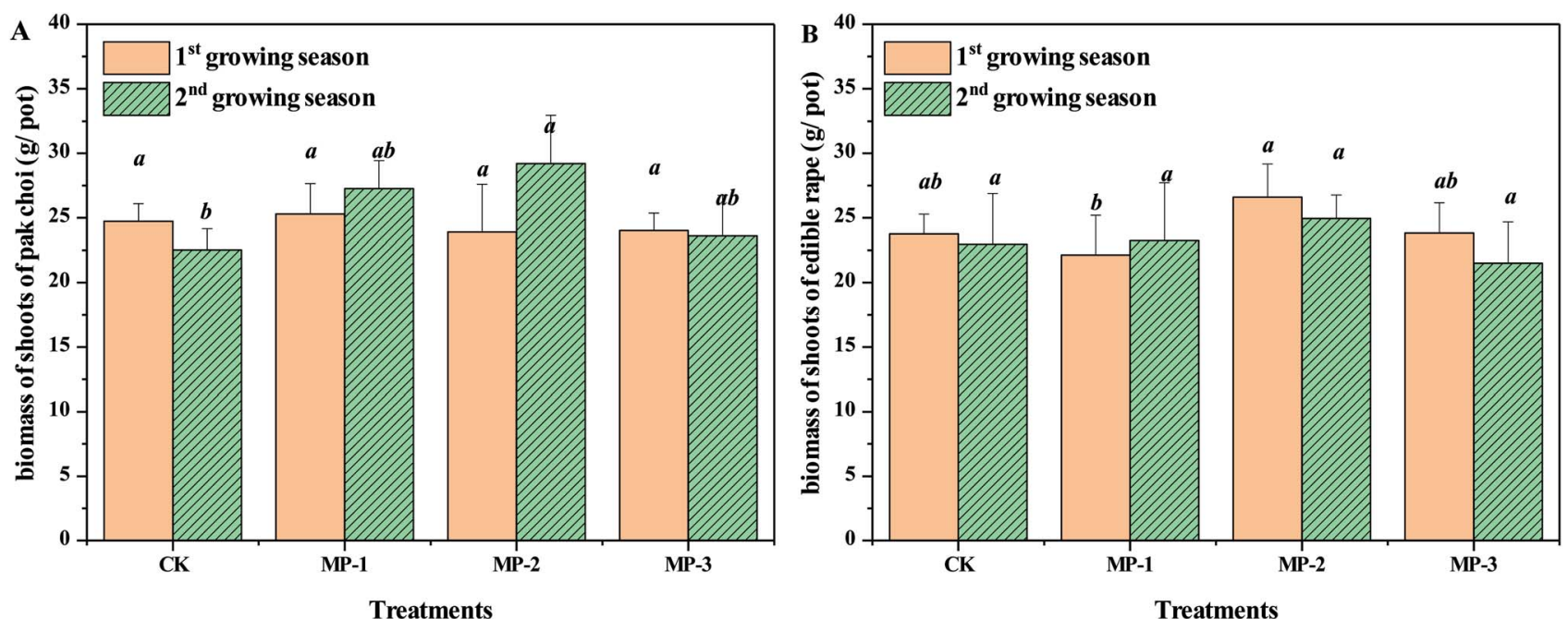

Fig. 1 Effects of MP on the total fresh biomass of pak choi. *The same letters within the individual error bars are not significantly different ( $p>$ 0.05); those with different letters are significantly different $(p<0.05)$. 

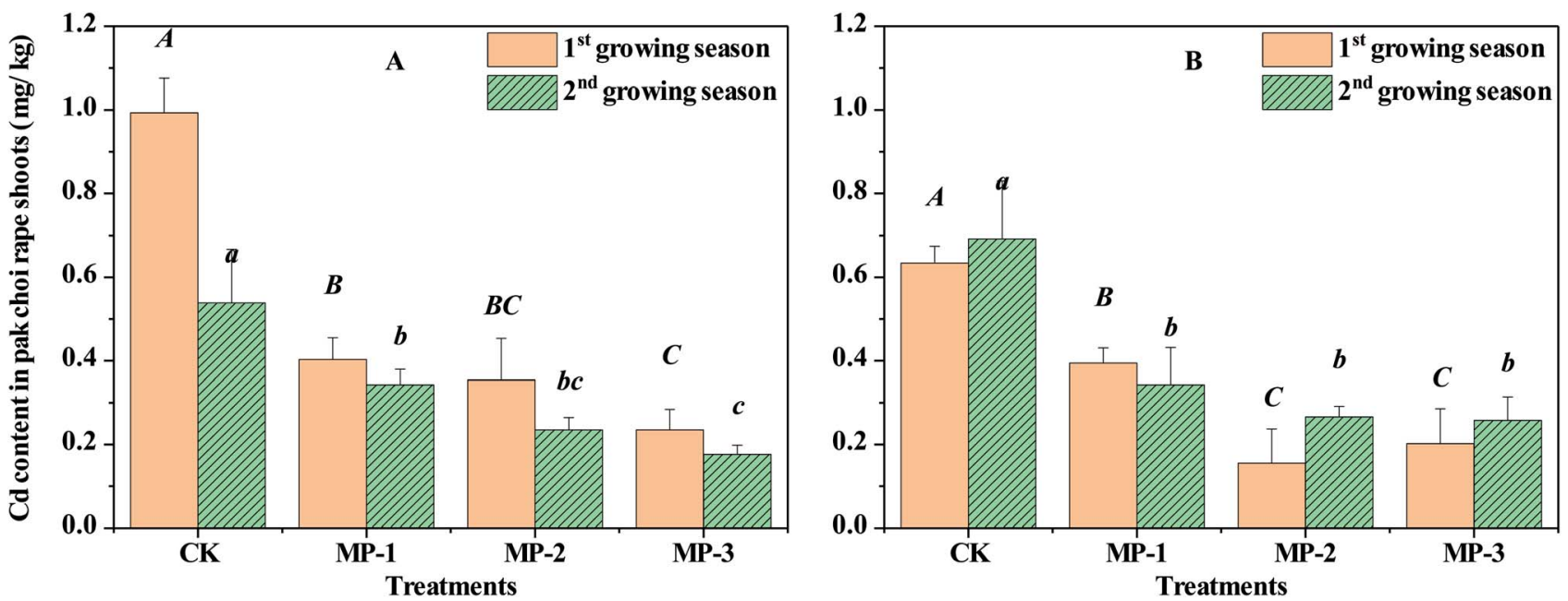

Fig. 2 Cd content in the pak choi shoots ((A) Guiyang soil; (B) Xiangtan soil).

significantly decreased Cd content in pak choi shoots compared to the CK. The MP Cd reduction effect in shoots was also observed in the second growing season, where Cd was reduced by $36.42-67.30 \%$ and $50.45-62.77 \%$ in Guiyang and Xiangtan soils, respectively. In the MP treatment groups, the minimum Cd content in shoots of pak choi were 0.17 and $0.15 \mathrm{mg} \mathrm{kg}^{-1}$, which is less than the maximum permitted level according to Chinese national standard (GB 2762-2017). The significant reduction of $\mathrm{Cd}$ accumulation in both roots and shoots of pak choi in consecutive growing seasons indicates stability of the Cd immobilization effect of MP.

In the actual remediation process, the relationship of remediation effects and application dosages of immobilization agents is important. Immobilization effects increase in significance at higher dosages, as shown in Fig. 2; however, for soil samples from Xiangtan, the $0.2 \%$ treatment had the most significant effect. These results indicate that there is an optimal soil specific dosage, likely due to the variety of complex physical and chemical properties in different soils. Therefore, in field demonstration experiments, the recommended dosage should be optimized in the range of $0.1-0.3 \%$. Pak choi is a leafy

Table $2 \mathrm{Cd}$ contents in the roots of pak choi ${ }^{a}$

Cd contents in the roots of edible rape $\left(\mathrm{mg} \mathrm{kg}^{-1} \mathrm{DW}\right)$

\begin{tabular}{llcl} 
Soil & Treatments & $1^{\text {st }}$ growing season & $2^{\text {nd }}$ growing season \\
\hline Guiyang soil & CK & $10.59 \pm 1.41 a$ & $4.74 \pm 0.52 a$ \\
& MP-1 & $6.92 \pm 1.01 b$ & $3.73 \pm 0.24 a b$ \\
& MP-2 & $7.94 \pm 1.43 b$ & $3.18 \pm 0.84 b c$ \\
Xiangtan soil & MP-3 & $4.08 \pm 0.84 c$ & $2.31 \pm 0.57 c$ \\
& MP-1 & $3.67 \pm 0.72 a$ & $7.75 \pm 1.85 a$ \\
& MP-2 & $1.91 \pm 0.37 b$ & $5.11 \pm 0.23 b$ \\
& MP-3 & $0.86 \pm 0.25 c$ & $1.97 \pm 0.56 c$
\end{tabular}

${ }^{a}$ The same letters following the numbers are not significantly different $(p$ $>0.05)$; those with different letters are significantly different $(p<0.05)$. vegetable which is more vulnerable to heavy metal contamination than other crops. ${ }^{26}$ The results obtained here are therefore representative of a worse-case $\mathrm{Cd}$ accumulation scenario, indicating that MP remediation likely also protective for a range of other crops.

Comparison of MP with other immobilization agents capable of reducing $\mathrm{Cd}$ accumulation in vegetables is shown in Table 3. Each agent has different immobilization effect; however, the overall efficiencies were lower than MP due to the large application dosages required to elicit the effect. For example, the dosage of limestone, red mud, and sepiolite was up to $5 \%$ in their respective studies..$^{27,28}$ The large application dosage may have adverse impacts on soil physical or chemical properties, such as soil compaction and alkalization. ${ }^{29}$ The greatest advantage of MP was the significant immobilization effect even at a minor dosage $(0.1 \%)$. In previous studies, it was determined that mercapto-grafted palygorskite at applied doses of $0.1-0.3 \%$ could significantly reduce $\mathrm{Cd}$ content in brown rice and other cultivars grown in water. ${ }^{30}$ The current study demonstrates that MP also has a significant immobilization effect in dry soils, increasing the applicability of MP immobilization remediation strategies. In situ soil application of MP as a novel immobilization agent may provide a cost-effective and sustainable solution for the remediation of contaminated soil.

\subsection{Changes of phytoavailable Cd fraction in soil samples}

The accumulation of $\mathrm{Cd}$ in pak choi is significantly positively correlated to the phytoavailable fraction, not the total $\mathrm{Cd}$ concentration in soils. MP has a significant reduction effect on phytoavailable Cd, determined by DGT, in consecutive growing seasons for both Guiyang and Xiangtan soils, Fig. 3. The phytoavailable $\mathrm{Cd}$ fraction decreased with increasing application dosage from $0.1 \%-0.3 \%$. The maximum reduction was $86.26 \%$ and $89.51 \%$, observed for the MP3 group for Guiyang soil and Xiangtan soil, respectively. The results provide direct evidence of the Cd immobilization effect facilitated by MP. In situ immobilization relies on the minimization of contaminant 
Table 3 Summary of some immobilization agents used for vegetables

\begin{tabular}{lllll}
\hline No. & Vegetable & Amendments & Dosage (weight ration) & $\begin{array}{c}\text { Reduction contents of } \\
\text { edible parts of vegetables }\end{array}$ \\
\hline 1 & Spinach & Sepiolite & $0.5-5 \%$ & $17.2-72.1 \%$ \\
2 & Spinach & Sepiolite & $1 \%, 5 \%$ & $22.8 \%$ and $30.1 \%$ \\
3 & Lettuce & Limestone, red-mud & $2 \%, 5 \%$ & $13-29 \%$ \\
4 & Brassica chinensis L & Synthetic zeolite & $0.3 \%, 0.6 \%, 1.0 \%$ & $4.6-35 \%$ \\
5 & Chinese cabbage & Lime & $10 \%$ & $22.4 \%$ \\
6 & Sinapis alba & Red mud & $5 \%$ & $18-29 \%$ \\
7 & Pakchoi & Biochar derived from manures & $2.5 \%, 5 \%$ & $34-76 \%$ and $33-72 \%$ \\
8 & Brassica chinensis L. & Cow manure-derived biochar & $3.0 \%, 6.0 \%$ & $51.2 \%$ and $67.4 \%$ \\
9 & Pak choi & Mercapto grafted palygorskite & $0.1 \%, 0.2 \%, 0.3 \%$ & $59.44-76.33 \%$
\end{tabular}

mobility, by promoting the transfer of metals from labile to non-labile phases via physical, chemical, or biological induced transformations. The DGT approach is preferable to traditional chemical extraction methods as it avoids errors resulting from the contamination of samples or use of sample treatments which may change the chemical form. ${ }^{16}$

\subsection{Changes of $\mathrm{pH}$ and zeta potential of soil samples}

Soil $\mathrm{pH}$ is an important parameter which affects the speciation and distribution of heavy metals in soils. Soil $\mathrm{pH}$ is the dominant driving factor which affects the surface charge and subsequent adsorption of solutes. ${ }^{31}$ As shown in Fig. 4, the average $\mathrm{pH}$ values in CK samples were 5.27 and 5.21 for Guiyang and Xiangtan soils respectively, indicating both are acidic soil. Acidified soil exacerbates the risk of migration and diffusion of heavy metals in soils. ${ }^{31}$ In both soils in the first and second the growing season, MP had no significant effect on soil $\mathrm{pH}(p>$ 0.05); however, soil $\mathrm{pH}$ did slightly decrease after the addition of MP in comparison to the CK. The lack of change in soil $\mathrm{pH}$ for MP is different than observed for other immobilization agents such as lime, biochar and red mud based passivator, ${ }^{6}$ where $\mathrm{pH}$ in intentionally increased to reduce the bioavailable fraction of heavy metals. Natural palygorskite without surface modification is an alkaline mineral with limited immobilization effects on heavy metals in paddy soils, but the introduction of the mercapto groups facilitated the creation of a sorption agent rather than a pH-regulating agent. Furthermore, the applied dosages $(0.1-0.3 \%)$ of MP are much less than dosages required for traditional $\mathrm{pH}$-regulating agents. MP was demonstrated to reduce $\mathrm{Cd}$ accumulation in shoots and roots of pak choi without altering soil $\mathrm{pH}$, indicating that $\mathrm{pH}$ is not the only factor which can impact the transfer of heavy metals in the plant-soil system.

Zeta potential is the electric potential in a shear plane at the solid-liquid interface; which is an important parameter for the adsorption capability of heavy metals. The zeta potential of Xiangtan and Guiyang soil samples in the first and second growing seasons measured as a function of $\mathrm{pH}$ are shown in Fig. 5. The zeta potentials of all soil particles were negative over the selected $\mathrm{pH}$ range and negativity increased with increasing of $\mathrm{pH}$. Lower zeta potential indicates greater negative charge at the soil particle surface at higher $\mathrm{pH} .{ }^{32}$ The reaction between $-\mathrm{OH}$ and $-\mathrm{SH}$ made the zeta potential of the soil particles more negative with increase in soil $\mathrm{pH}$. Compared to soil particles in the CK, MP decreased zeta potentials of soil, even at the minimum dose $(0.1 \%)$, which benefitted the sorption of heavy metal cations to soil particles. The results presented here are consistent with the conclusions of others, for example, pectin added to soils decreased zeta potential
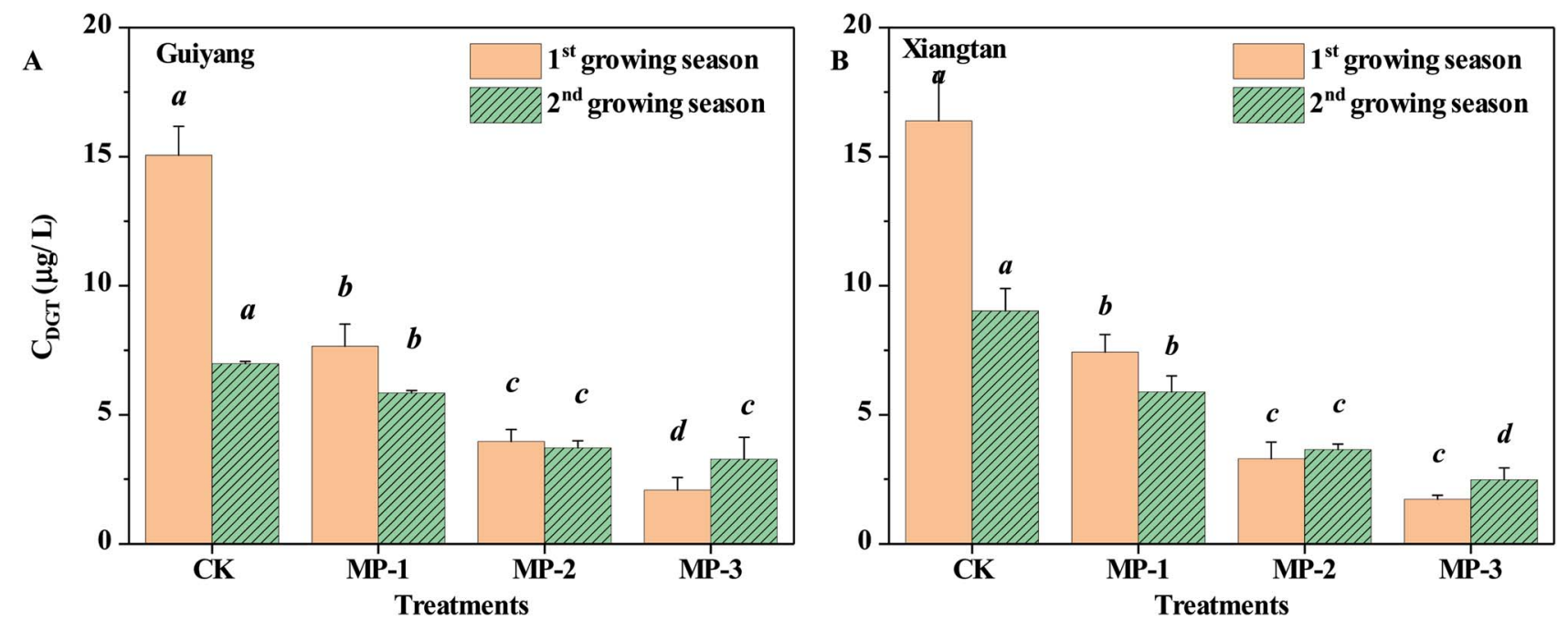

Fig. 3 Phytoavailable Cd contents determined using the DGT technique ((A) Guiyang soil; (B) Xiangtan soil). 

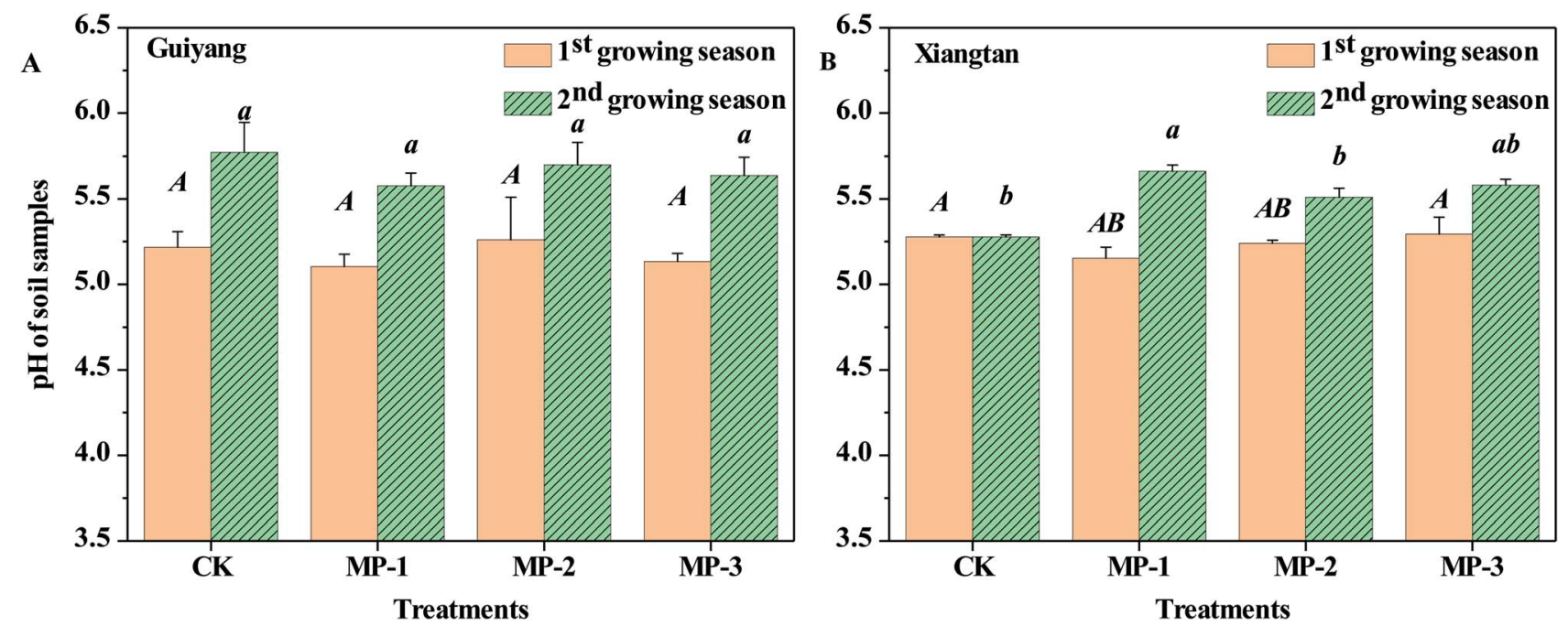

Fig. $4 \mathrm{pH}$ of the soil samples ((A) Guiyang soil; (B) Xiangtan soil).

of soil colloids and made the charge on soils more negative, which was responsible for an observed increase in the electrostatic adsorption of $\mathrm{Cu}^{2+} \cdot{ }^{33}$ Biochar also decreased the zeta potential and increased the negative charge of soil, thus increased $\mathrm{Cd}^{2+}$ was adsorbed to soil via electrostatic interactions. ${ }^{34}$ Furthermore, biochar derived from crop straws also enhanced the absorption of $\mathrm{Cd}^{2+}$ to soils with variable charges through both electrostatic and non-electrostatic mechanisms. ${ }^{35}$ The effect of MP on the variable charge and point of zero charge in soils should be investigated in further research.
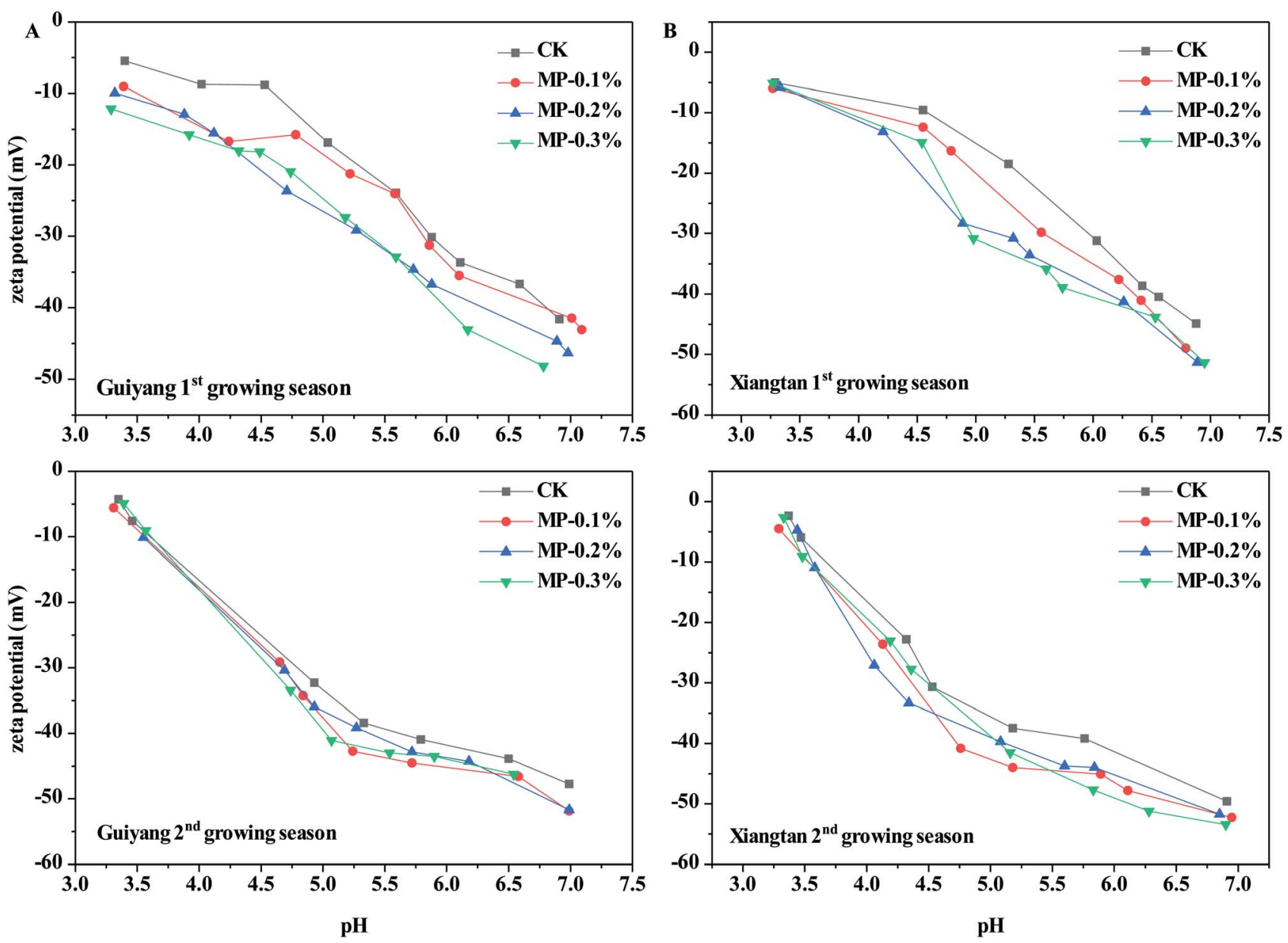

Fig. 5 Zeta potentials of the soil samples ((A) Guiyang soil; (B) Xiangtan soil). 


\subsection{Sorption amounts of $\mathrm{Cd}^{2+}$ on soil samples}

The nature of sorption and desorption processes affects both metal solubility and bioavailability in soil. Sorption of $\mathrm{Cd}^{2+}$ to the soil is depicted in Fig. 6 . The maximum sorption capacity for $\mathrm{Cd}^{2+}$ increased compared to $\mathrm{CK}$ for both soil types $(p<0.05)$. The improved soil adsorption capacity for $\mathrm{Cd}^{2+}$ resulted from the higher metal adsorption affinity of MP. ${ }^{36}$ Natural soils are complex and include clay minerals, Fe/Mn oxides, and organic matter; all of which have predominantly -OH sorption sites, suitable for reactions with heavy metal cations. ${ }^{37} \mathrm{MP}$ can also remove heavy metals such as $\mathrm{Cd}^{2+}$ and $\mathrm{Cu}^{2+}$ from aqueous solutions efficiently by mercapto groups providing a supply of sorption sites. ${ }^{38,39}$ Mercapto groups strongly bond with heavy metal ions such as $\mathrm{Hg}^{2+}, \mathrm{Cd}^{2+}$, and $\mathrm{Cu}^{2+}$, according to Pearson's hard-soft acid-base theory. Mercapto modified silica particles also have a strong affinity for heavy metals such as $\mathrm{Hg}^{2+}, \mathrm{Cd}^{2+}$, and $\mathrm{Pb}^{2+} \cdot{ }^{40}$ Therefore, the observation of increasingly negative zeta potential in soils after the addition of MP and resulting increases in heavy metal soil sorption capacity, is aligned with previous findings. For example, biochar from rice straws added to three variable charge soils induced a significant shift of zeta potential in the negative direction, ${ }^{41}$ which resulted in greater adsorption of $\mathrm{Cd}^{2+} \cdot{ }^{42}$ The application of biochar and compost at various ratios all significantly increased the adsorption capacity of studied soils for metals. ${ }^{36}$ Phosphate added to red soil decreased the soil zeta potential, while net negative charges on the surface increased, leading to the enhancement of $\mathrm{Pb}^{2+}$ electrostatic adsorption. ${ }^{43}$ The addition of MP enhanced the sorption of bioavailable Cd to soil, which could be a remediation mechanism of MP.

\subsection{Changes of available sulfur contents in soil samples}

The accessible content of mercapto groups in MP was approximately $1.6 \mathrm{mmol} \mathrm{g}^{-1}$. Compared to the CK, available sulfur content in both soils in consecutive growing seasons increased with increasing application dosage $(p<0.05)$, Fig. 7. The minimum available sulfur content was 82.88 and $92.71 \mathrm{mg} \mathrm{kg}^{-1}$ for the Guiyang and Xiangtan soil, respectively. The critical value of available sulfur in soil required for normal growth of pak choi in China was determined to be $21.1 \mathrm{mg} \mathrm{kg}^{-1} \cdot{ }^{44}$ In the first and second growing season, the maximum increase of available sulfur was $67.95 \%$ and $47.03 \%$ in Guiyang and Xiangtan soils, respectively. Cd contents in the shoots of pak choi decreased with the increase of available sulfur content in soils, but linear relationship was not found. The results indicate that sulfur may play an important role in the remediation process. It was reported that sulfur could affect cadmium solubility in paddy soils by soil oxidation and formations of metal sulfides. When sulfur was added, Cd solubility decreased, due to the precipitation of sulfide minerals under anaerobic conditions. ${ }^{45}$ Excessive sulfur supply significantly decreased Cd accumulation in brown rice in a combined soil and sand pot experiment. ${ }^{46}$ The species of sulfur and the relationship of available sulfur in soil samples and the accumulation of Cd in the shoots of pak choi should be investigated in further research.

\subsection{Changes of activities of POD, CAT, UE and SC of soil samples}

Soil enzymes play an important role in soil microbial ecology by catalyzing various reactions. ${ }^{47}$ Enzymes are an important component of soil biochemistry to assess because changes in soil enzymes induced by remediation agents could impact soil health. Soil enzyme activity is affected by many factors such as soil $\mathrm{pH}$, organic matter content, nutrient availability, and microbial species. Heavy metals can inhibit or activate soil enzyme activity. At the same time, changes in soil enzyme activity could impact the release of nutrients and subsequently the growth of crops. The analyses of soil enzyme activity will help assess the effects of heavy metal contamination on soil biochemistry.

Urease is an important enzyme in the transformation of nutrients involved in soil nitrogen cycling. ${ }^{48}$ In the current
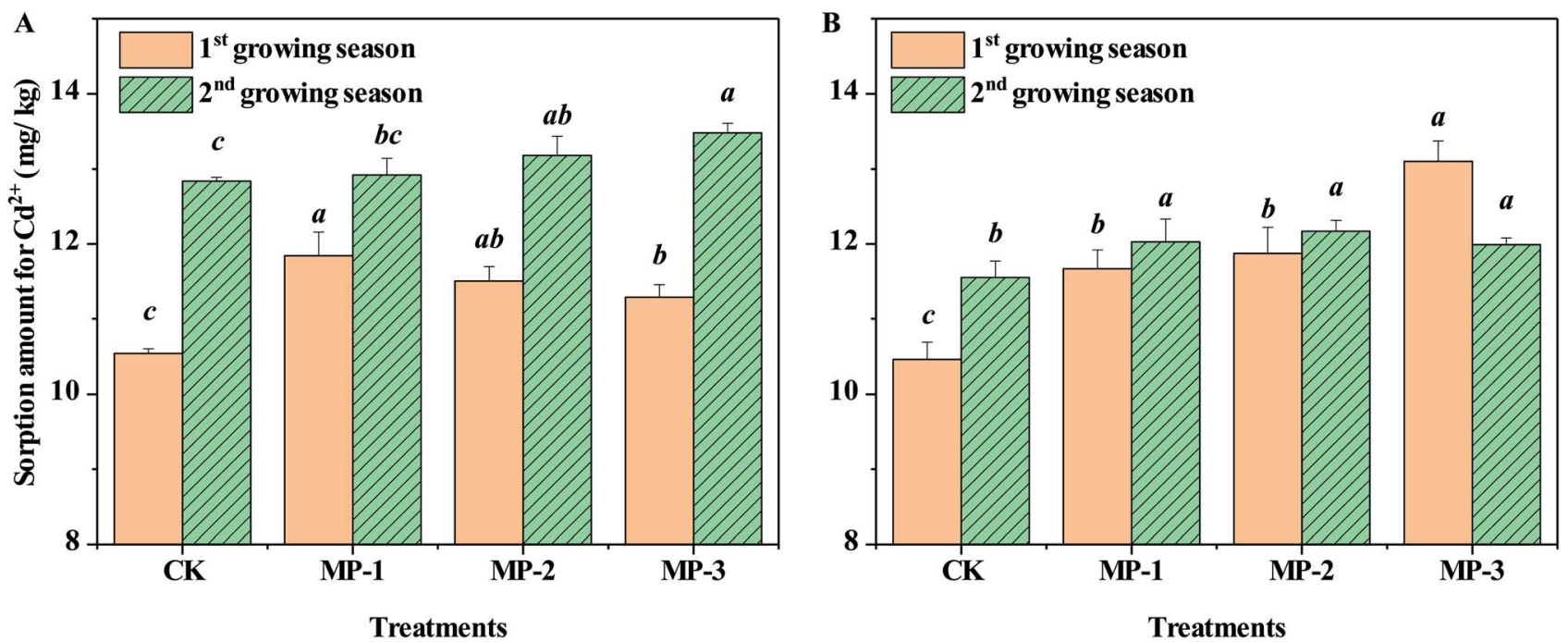

Fig. 6 Cd sorption amounts on the soil samples ((A) Guiyang soil; (B) Xiangtan soil). 

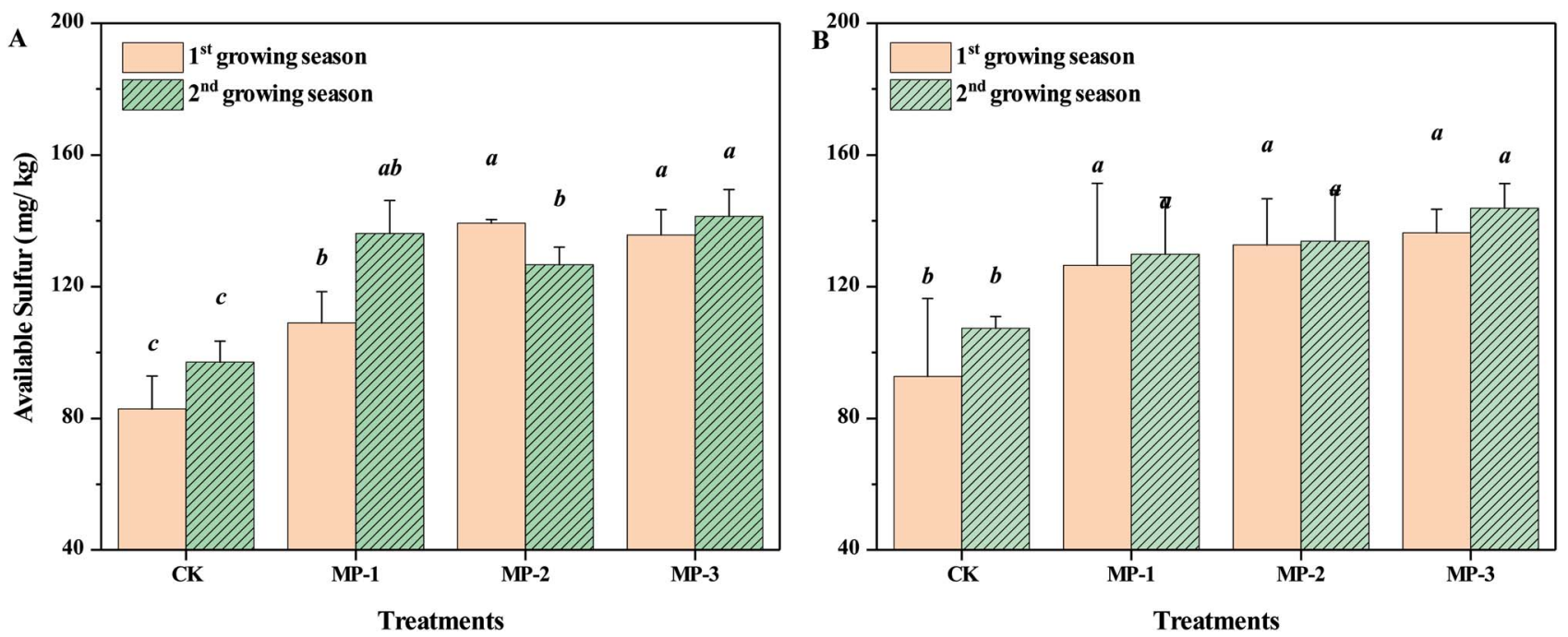

Fig. 7 Available sulfur contents in the soil samples ((A) Guiyang soil; (B) Xiangtan soil).

study, MP treatments increased urease activity in Xiangtan and Guiyang soils, with the exception of Guiyang soil in the second growing season, Table 4 . The results suggest another benefit using MP for Cd remediation, increased urease activity. This in similar to the findings of others where, compared to nonamended soil, urease activity was higher in limestone- and red-mud-amended soils. ${ }^{27}$ Catalase breaks the chemical bonds in hydrogen peroxide to release molecular oxygen and water, thus preventing reactive oxygen species from damaging cells. Catalase activity may be related to the metabolic activity of aerobic organisms and has been used as an indicator of soil fertility. For Guiyang soil, in the first and second growing seasons, there was no significant difference in catalase activities between the MP treatments and the CK. In contrast, catalase activity in Xiangtan soil in the first growing season was obviously enhanced by MP treatments compared to the CK. Peroxidase activity in both soils in the consecutive growing seasons increased after the addition of MP compared to CK; however, there were no significant statistical difference between CK and MP treatments. Further, based on the data presented in Table 4, the effects of MP on invertase activities in both soil samples can be ignored.

It has been reported that urease and catalase activities are key microbial parameters that affect heavy metal accumulation in rice by influencing the bioavailability of heavy metals in soil or the translocation of heavy metals in rice. ${ }^{49}$ It was also determined that $\mathrm{Cd}$ contents in rice grains were significantly and negatively associated with soil urease and catalase

Table 4 Activities of urease, catalase, peroxidase, and sucrase in the soil samples ${ }^{a}$

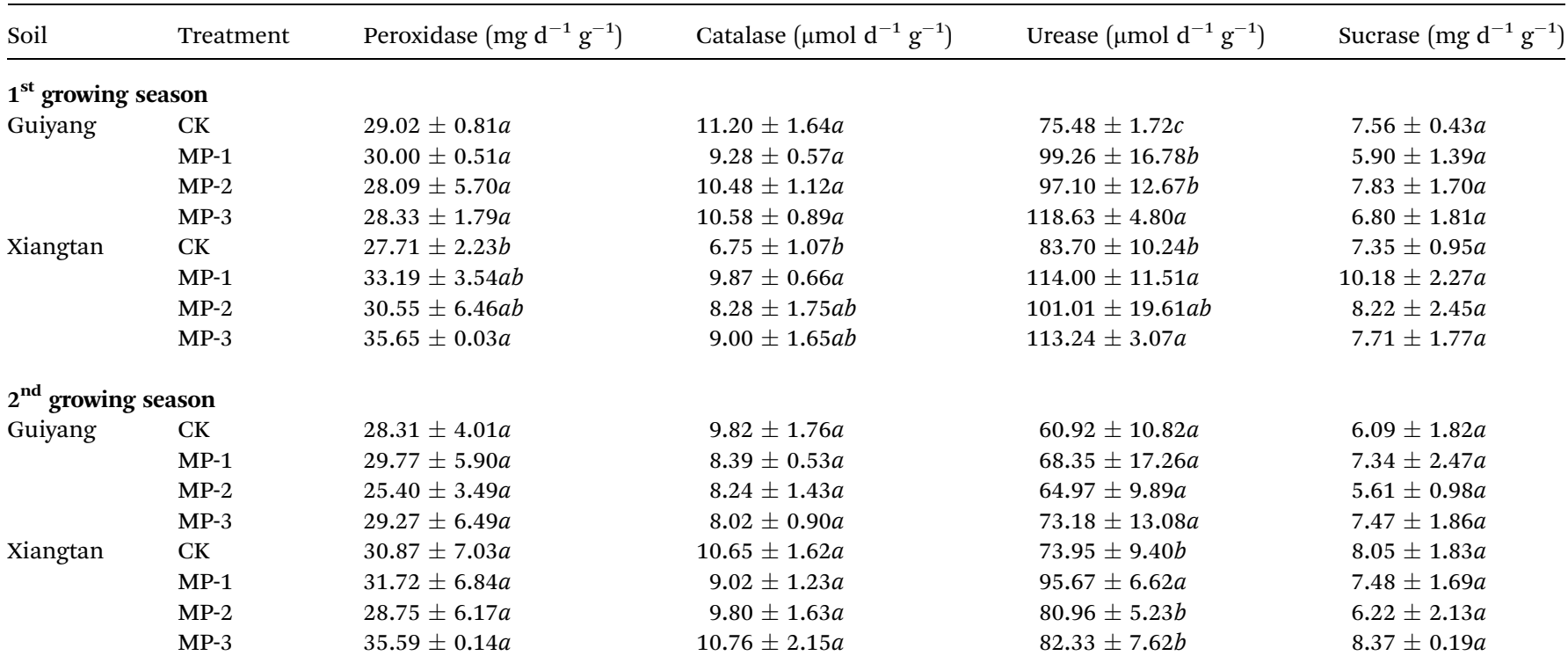

${ }^{a}$ The same letters following the numbers are not significantly different $(p>0.05)$; those with different letters are significantly different $(p<0.05)$. 


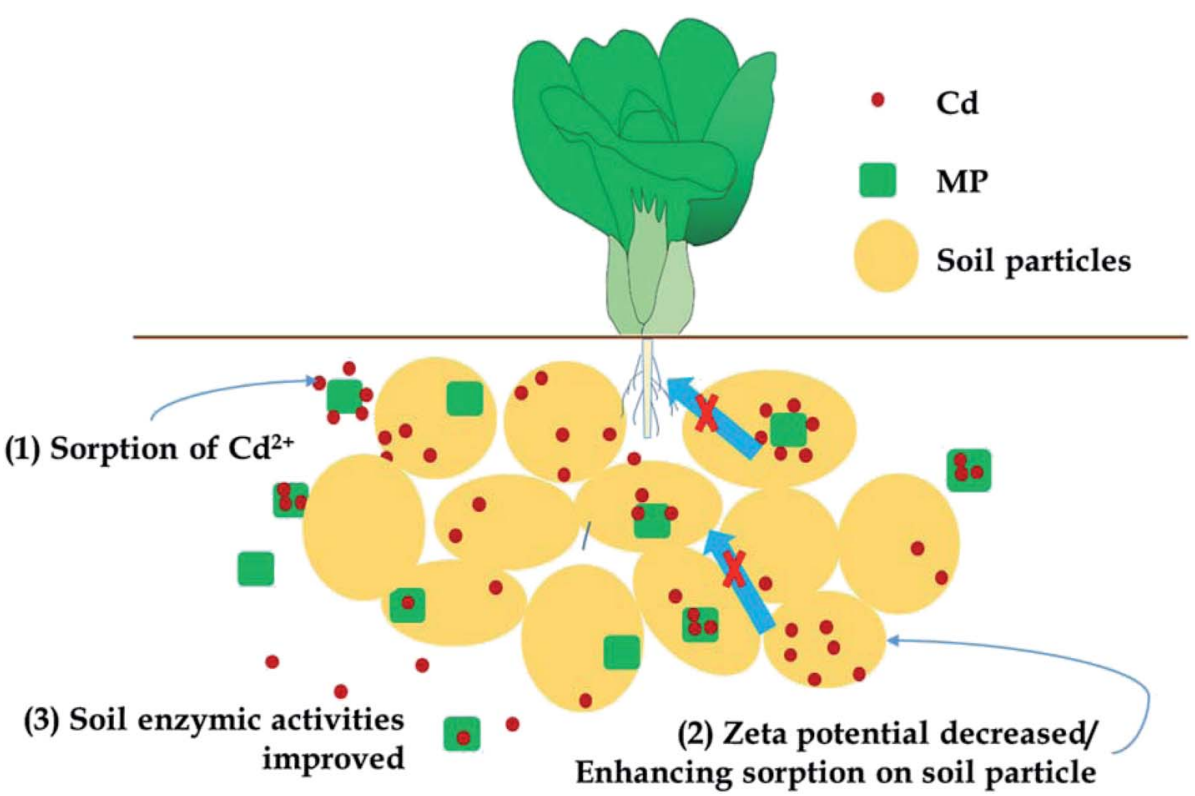

Fig. 8 General mechanism by which MP reduces $\mathrm{Cd}$ accumulation in pak choi.

activity. ${ }^{49}$ Furthermore, significant increases in urease and catalase activity accompanied by a reduction in exchangeable $\mathrm{Cd}$ in soils were observed after biochar addition..$^{50}$ Both bamboo and rice straw biochar were shown to be effective in decreasing bioavailable $\mathrm{Cu}$ and $\mathrm{Pb}$ from soil, and also accompanied by increased urease and catalase activity. ${ }^{51}$ Thus, the results of current research are consistent with previous findings.

\subsection{Remediation mechanisms}

The remediation mechanism determines the long-term stability and environmental sensitivity of the remediation process. If remediation agents exert their effects through a pH-regulating effect, liming effect, or electrostatic adsorption, then remediation is highly sensitive to changes in soil $\mathrm{pH}$, which could be affected by acid rain or other environmental changes. An unintended soil $\mathrm{pH}$ change will alter phytoavailability and the risks posed by heavy metals could return. If the remediation mechanism promotes the immobilization or fixation of heavy metals in the soil through chemical adsorption or precipitation, the immobilized heavy metals will be more resilient to environmental changes (e.g., $\mathrm{pH}$, redox). ${ }^{52} \mathrm{~A}$ schematic of the general remediation mechanisms of MP in current research is presented in Fig. 8. As mentioned before, MP has been demonstrated to reduce $\mathrm{Cd}$ accumulation in pak choi and reduce the available $\mathrm{Cd}$ fraction in soils from different locations in consecutive growing seasons, indicating a significant remediation effect. MP exhibited no effect on $\mathrm{pH}$ in both soils over consecutive growing seasons, which was different from other pH-regulating immobilization agents; however, the increased sorption amounts of $\mathrm{Cd}$ on soil particles in sorption experiments indicated could enhance chemical sorption of heavy metal cations by decreasing soil surface zeta potential, which resulted in the reduction of the phytoavailable fraction of heavy metals in soils. Additional, as studied before, as an excellent adsorbent, MP was also demonstrated to adsorb heavy metal cations in soil solutions directly, which could be regarded as an indirect remediation mechanism, just like other immobilization agent such as modified biochar. ${ }^{4}$ Finally, in the aspect of soil microbiology, MP increased certain enzyme activities in soils, which could be important for alleviating the stress heavy metals cause to plants.

\section{Conclusions}

MP could significantly reduce Cd accumulation in the shoots and roots of pak choi grown in Xiangtan and Guiyang soils compared to the control, in consecutive growing seasons. Further, MP decreased the phytoavailable Cd content in soil determined using the DGT technique, and the immobilization effect could remain in consecutive growing seasons. In the aspect of soil chemistry, MP had no obvious effect on the $\mathrm{pH}$ values of both soils, but increased available sulfur content and decreased the zeta potential of both soils, and increased the sorption amounts of Cd on soil particles. MP could achieve the purpose of remediation effects by enhancing the sorption of Cd contaminants on soil particles and the chemical sorption of $\mathrm{Cd}^{2+}$ on MP itself. In the aspect of soil microbiology, MP also increased certain soil enzyme activities, such as that of urease, alleviating Cd-induced oxidative stress, which indicates the environmental-friendly nature of MP. The high-performances of MP at low dosages confirm that MP has great potential for large-scale applications to reduce $\mathrm{Cd}$ accumulation in vegetables.

\section{Conflicts of interest}

There are no conflicts to declare. 


\section{Acknowledgements}

The current research was supported by the Funds for Science and Technology Innovation Project from the Chinese Academy of Agricultural Sciences (No. CAAS-XTCX-2016018) and Modern Agricultural Industry R\&D System in China (CARS-03).

\section{References}

1 Y. Du and Y. Zhao, Sci-Tech Information Development and Economy, 2005, 15, 139-140.

2 Y. Xu, X. Liang, Y. Xu, X. Qin, Q. Huang, L. Wang and Y. Sun, Pedosphere, 2017, 27, 193-204.

3 D. Chen, X. Liu, R. Bian, K. Cheng, X. Zhang, J. Zheng, S. Joseph, D. Crowley, G. Pan and L. Li, J. Environ. Manage., 2018, 222, 76-85.

4 Y. Zhou, X. Liu, Y. Xiang, P. Wang, J. Zhang, F. Zhang, J. Wei, L. Luo, M. Lei and L. Tang, Bioresour. Technol., 2017, 245, 266-273.

5 B. Li, J. Yang, D. Wei, S. Chen, J. Li and Y. Ma, PLoS One, 2014, 9, e109967.

6 H. Li, Y. Liu, Y. Zhou, J. Zhang, Q. Mao, Y. Yang, H. Huang, Z. Liu, Q. Peng and L. Luo, Sci. Total Environ., 2018, 640-641, 736-745.

7 H. Li, L. Liu, L. Luo, Y. Liu, J. Wei, J. Zhang, Y. Yang, A. Chen, Q. Mao and Y. Zhou, Environ. Sci. Pollut. Res., 2018, 25, 11661-11669.

8 A. Yao, Y. Wang, X. Ling, Z. Chen, Y. Tang, H. Qiu, R. Ying and R. Qiu, Environ. Geochem. Health, 2017, 39, 353-367.

9 R. Chen, C. Zhang, Y. Zhao, Y. Huang and Z. Liu, Environ. Sci. Pollut. Res., 2018, 25, 2361-2368.

10 S. Li, S. Zhang, X. Ding, X. Liao and R. Wang, Procedia Environ. Sci., 2013, 18, 68-77.

11 S. Zhu, Y. Liang, D. Gao, X. An and F. Kong, Sci. Hortic., 2017, 218, 87-94.

12 F. Nawaz, R. Ahmad, M. Y. Ashraf, E. A. Waraich and S. Z. Khan, Ecotoxicol. Environ. Saf., 2015, 113, 191-200.

13 H. Zong, K. Li, S. Liu, L. Song, R. Xing, X. Chen and P. Li, Chemosphere, 2017, 181, 92-100.

14 B.-Y. He, D.-P. Yu, Y. Chen, J.-L. Shi, Y. Xia, Q.-S. Li, L.-L. Wang, L. Ling and E. Y. Zeng, Chemosphere, 2017, 171, 588-594.

15 W. Liu, Q. Zhou, Y. Zhang and S. Wei, J. Environ. Manage., 2010, 91, 781-788.

16 C. Zhang, S. Ding, D. Xu, Y. Tang and M. H. Wong, Environ. Monit. Assess., 2014, 186, 7367-7378.

17 M. Rizwan, S. Ali, M. Adrees, M. Ibrahim, D. C. W. Tsang, M. Zia-ur-Rehman, Z. A. Zahir, J. Rinklebe, F. M. G. Tack and Y. S. Ok, Chemosphere, 2017, 182, 90-105.

18 X. Liang, Y. Xu, X. Tan, L. Wang, Y. Sun, D. Lin, Y. Sun, X. Qin and Q. Wang, Colloids Surf., A, 2013, 426, 98-105.

19 Y. Dai, M. Nasir, Y. Zhang, J. Gao, Y. Lv and J. Lv, Chemosphere, 2018, 191, 183-189.

20 L. Zhang, Q. Sun, S. Ding, X. Cheng, Q. Liu and C. Zhang, Environ. Sci. Pollut. Res., 2017, 24, 15727-15734.

21 J. Jiang, R. Xu, Y. Wang and A. Zhao, Chemosphere, 2008, 71, 1469-1475.
22 V. J. Kilmer and D. C. Nearpass, Soil Sci. Soc. Am. J., 1960, 24, 337-340.

23 S. Deng and I. Popova, in Methods of Soil Enzymology, ed. R. P. Dick, Soil Science Society of America, Madison, WI, 2011, pp. 185-209, DOI: 10.2136/sssabookser9.c9.

24 E. Kandeler, C. Poll, W. T. Frankenberger and M. A. Tabatabai, in Methods of Soil Enzymology, ed. R. P. Dick, Soil Science Society of America, Madison, WI, 2011, DOI: 10.2136/sssabookser9.c10, pp. 211-245.

25 J. A. Prosser, T. W. Speir and D. E. Stott, in Methods of Soil Enzymology, ed. R. P. Dick, Soil Science Society of America, Madison, WI, 2011, DOI: 10.2136/sssabookser9.c6, pp. 103-124.

26 J. Wang, W. Fang, Z. Yang, J. Yuan, Y. Zhu and H. Yu, J. Agric. Food Chem., 2007, 55, 9118-9123.

27 S.-H. Lee, J.-S. Lee, Y. Jeong Choi and J.-G. Kim, Chemosphere, 2009, 77, 1069-1075.

28 Y. Sun, Y. Xu, Y. Xu, L. Wang, X. Liang and Y. Li, Environ. Pollut., 2016, 208, 739-746.

29 H. Kang, J. Lin, N. Zhang, L. Bao and B. Liu, Chinese Agricultural Science Bulletin, 2015, 31, 176-180.

30 X. Liang, X. Qin, Q. Huang, R. Huang, X. Yin, Y. Cai, L. Wang, Y. Sun and Y. Xu, Environ. Sci. Pollut. Res., 2017, 24, 2378323793.

31 L. Blake, in Encyclopedia of Soils in the Environment, ed. D. Hillel, Elsevier, Oxford, 2005, DOI: 10.1016/B0-12-348530-4/ 00083-7, pp. 1-11.

32 F. V. Molina, in Soil Colloids: Properties and Ion Binding, ed. F. V. Molina, CRC Press, Boca Raton 2013, DOI: 10.1201/ b15349-7, pp. 111-158.

33 R.-h. Wang, X.-f. Zhu, W. Qian, Y.-c. Yu and R.-k. Xu, Environ. Sci. Pollut. Res., 2015, 22, 19687-19694.

34 Y. Wang, D. Tang, X. Zhang, X. Yuan and L. Xu, J. AgroEnviron. Sci., 2017, 36, 2445-2452.

35 R.-k. Xu and A.-z. Zhao, Environ. Sci. Pollut. Res., 2013, 20, 8491-8501.

36 Z. Yang, J. Liang, L. Tang, G. Zeng, M. Yu, X. Li, X. Li, Y. Qian, H. Wu, Y. Luo and D. Mo, J. Soils Sediments, 2018, 18, 15301539.

37 M. K. Uddin, Chem. Eng. J., 2017, 308, 438-462.

38 J. Han, X. Liang, Y. Xu and Y. Xu, J. Ind. Eng. Chem., 2015, 23, 307-315.

39 X. Liang, J. Han, Y. Xu, L. Wang, Y. Sun and X. Tan, Appl. Surf. Sci., 2014, 322, 194-201.

40 K. Aljoša, L. Aleksandra and B. Maja, Int. J. Appl. Ceram. Technol., 2015, 12, 461-472.

41 J. Jiang, R.-k. Xu, T.-y. Jiang and Z. Li, J. Hazard. Mater., 2012, 229-230, 145-150.

42 J. Tian-yu, J. Jun, X. Ren-kou and Z. Li-xiang, J. Agro-Environ. Sci., 2012, 31, 1111-1117.

43 J. C. Zuo, Q. L. Fu, X. J. Su, Y. H. Liu, J. Zhu, H. Q. Hu and Y. J. Deng, Environ. Prog. Sustainable Energy, 2016, 35, 969974.

44 B. Lin, S. Li and W. Zhou, Plant Nutr. Fert. Sci., 2000, 6, 436445. 
45 J. De Livera, M. J. McLaughlin, G. M. Hettiarachchi, J. K. Kirby and D. G. Beak, Sci. Total Environ., 2011, 409, 1489-1497.

46 J.-L. Fan, Z.-Y. Hu, N. Ziadi, X. Xia and C.-Y.-H. Wu, Environ. Pollut., 2010, 158, 409-415.

47 P. Bhattacharyya, S. Tripathy, K. Kim and S.-H. Kim, Ecotoxicol. Environ. Saf., 2008, 71, 149-156.

48 S. Tripathi, A. Chakraborty, K. Chakrabarti and B. K. Bandyopadhyay, Soil Biol. Biochem., 2007, 39, 28402848.

49 L. Xiao, D. Guan, M. R. Peart, Y. Chen, Q. Li and J. Dai, Chemosphere, 2017, 185, 868-878.

50 C. Nie, X. Yang, N. K. Niazi, X. Xu, Y. Wen, J. Rinklebe, Y. S. Ok, S. Xu and H. Wang, Chemosphere, 2018, 200, 274282.

51 X. Yang, J. Liu, K. McGrouther, H. Huang, K. Lu, X. Guo, L. He, X. Lin, L. Che, Z. Ye and H. Wang, Environ. Sci. Pollut. Res., 2016, 23, 974-984.
52 R. E. Hamon, M. J. McLaughlin and G. Cozens, Environ. Sci. Technol., 2002, 36, 3991-3996.

53 Y. Sun, G. Sun, Y. Xu, L. Wang, X. Liang and D. Lin, Geoderma, 2013, 193-194, 149-155.

54 A. Hussain Lahori, Z. Zhang, Z. Guo, A. Mahar, R. Li, M. Kumar Awasthi, T. Ali Sial, F. Kumbhar, P. Wang, F. Shen, J. Zhao and H. Huang, Ecotoxicol. Environ. Saf., 2017, 145, 313-323.

55 V. Feigl, A. Anton, N. Uzigner and K. Gruiz, Water, Air, Soil Pollut., 2012, 223, 1237-1247.

56 K. Yasmin Khan, B. Ali, X. Cui, Y. Feng, X. Yang and P. Joseph Stoffella, Ecotoxicol. Environ. Saf., 2017, 141, 129138.

57 Y. K. Kiran, A. Barkat, X.-q. Cui, Y. Feng, F.-s. Pan, L. Tang and X.-e. Yang, J. Integr. Agric., 2017, 16, 725-734. 